Bangladesh Journal of Bioethics 2020; 11 (3): 1-8

\title{
A survey on the attitude of college students to the privacy right as opposed to the right to know
}

\author{
Nader Ghotbi, MD, PhD
}

Professor, College and Graduate School of Asia Pacific Studies Ritsumeikan Asia Pacific University (APU), Beppu City, Japan

Email: nader@apu.ac.jp

https://doi.org/10.3329/bioethics.v11i3.50591

\begin{abstract}
There are times when two essential human rights may appear to be in conflict, or need to be balanced against one another. This paper examines the right of a party, such as officials, a group of people or an individual, to 'privacy and confidentiality' when others may have a conflicting 'right to know' about them. Although similar conflicts have been studied by other researchers, there is still controversy over the rightful balance in situations driven by new information and communication technologies. I conducted a survey on the attitude of college students to the privacy right versus the right to know using an actual case at the university. First, I asked the students if they believed protecting the privacy of a married teacher who had fathered a child with a student was more important than the right of the school to know. Second, I asked if they believed a child born to a single mother in such a relationship has the right to know about his father, or the single mother has the right to keep that information confidential. Third, I asked the students if they believed in general that the 'right to privacy and confidentiality' was more important or the 'right to know'. This paper reports on the results of this survey on 222 students at an international university in Japan.
\end{abstract}

Keywords: College students, human rights, right to know, right to privacy, survey research.

(Some part of this article has been presented at the 20 th Asian Bioethics Conference, 22-25 November 2019, Dhaka, Bangladesh).

Introduction: In USA, the public 'right to know' was first suggested as a specific legal concept by Cooper in 1956 who was the director of a news agency at the time ${ }^{1}$. The right to know in his view meant ensuring that citizens would have access to information essential for protecting democracy. Emerson emphasized on the right to know as the basis for acquiring the needed information, and the communication of the information to others so that the freedom of expression would be realized $^{2}$. John De Mott discussed the necessity of citizens' access to governmental and public information for scrutiny while protecting the privacy of citizens from unwanted exposure ${ }^{3}$. He also emphasized that there could be situations of conflict between the two in which finding a balance could be a difficult task. However, according to him, the US constitution did not provide assurance for neither of these rights and courts could have their own interpretation, except for one general rule: citizens' privacy must be protected unless disclosure of information is in the public interest. Situations may change; therefore, setting laws may not satisfy the dynamic need to balance the right to privacy against the right to know in every instance. An example is provided by Baker who referred to the need 
of the schools to access students' data to deal with increasing acts of violence in school while a recent law had limited such access to ensure educational data of students would not be misused by third parties ${ }^{4}$.

Viano pointed at factors that influenced the activity of media regarding criminal information related to individuals who needed to protect themselves against unwarranted exposure ${ }^{5}$. Viano emphasized on the role of social, cultural, and political forces in moving the balance to one way or the other which underscores the need of the society to develop policy based on a code of ethics. It can be said that the media play a significant role in gauging the public view as well as the legal system's ruling over an acceptable line between the right to know versus the right to privacy.

As Harris has noted, Hippocrates stressed on the physicians' responsibility over the confidentiality of their patients' medical issues in the $4-5^{\text {th }}$ century B.C $C^{6}$. That is why the Hippocratic Oath includes a statement on the privacy of patients' medical information. Without this sort of medical privacy, it is hard to create the needed trust in patients to provide the physician with all private information needed to make a diagnosis. However, the modern systems for management of medical information are far too complex to be maintained by a physician's oath; meanwhile, these systems help provide the benefit of integrated access to the information by various healthcare departments. Wyld et al. discussed the challenges in the delicate balance of the privacy and confidentiality rights of HIV positive people versus the right to know of other patients and anyone else who might be affected by the risk of exposure to $\mathrm{HIV}^{7}$.

Pape examined the situation where the public may benefit from access to more information about their doctors' record of practice, while that might cause a change in the practice of physicians towards defensive medicine and finally leave the patients worse off, with a general decline in healthcare quality ${ }^{8}$. Borna and Avila discussed the issue of the need for confidentiality of citizens' genetic information and its delicate balance, including the right of insurance companies to know about them to manage their risk ${ }^{9}$. However, access to such information might lead to significantly higher cost of health insurance or its denial from high-risk individuals because of their genetic makeup.

Gross discussed the fragility of democracies and the need for continuous vigilance to protect them through the right to know and access to information, though that may conflict with the citizens' right to privacy in some instances ${ }^{10}$. The important issue would be finding the right balance to the periled situation of safety and security in countries where terrorism became a real threat after the September 11 terrorist attacks on the US. On the other hand, many countries around the world have used the terrorism threat as an excuse to downplay the citizens' right to privacy and confidentiality over their personal information and in some cases even legal entities have infringed on the rights of citizens. Such examples demonstrate the challenges facing ethical philosophers in balancing the right to privacy versus the right 
to know in a dynamic, modern and technologically driven world where information plays an important role in every aspect of the life of citizens.

Deloney pointed to the result of studies that showed most adopted children as well as their birth parents wanted to have access to birth records while many US states limited such access to protect the privacy rights envisioned by law ${ }^{11}$. Banisar has suggested that the right to privacy and the right to know may together help hold governments accountable to citizens, but the potential conflict between them may lead to controversial situations where mechanisms are needed to reduce conflict and balance the rights $^{12}$. Symons discussed the 2016 change in Australian law whereby donor-conceived children were given the right to access information of anonymous donors, including their name, date of birth, ethnicity, physical characteristics and genetic conditions, even if the donor had requested anonymity ${ }^{13}$. Apparently, the right to know won over the right to privacy in this case. But there are other cases arising in both the healthcare sector as well as social policy, information security and governance ${ }^{14}$.

Some laws may already exist to help clarify the rightful balance in situations where a conflict arises between the right to privacy versus the right to know, such as leaning on the right of the community 'to know' about a sex offender having a criminal history who takes residence in a neighborhood ${ }^{15}$. However, the law may not specify what should be done in countless other examples. For instance, researchers in Pakistan examined whether a nurse should notify others to sexual abuse of a housewife by her husband when the hospital and local tradition insisted on keeping silent about it to presumably protect the privacy of the married couple ${ }^{16}$. This example demonstrates the role of culture and cultural differences in determining the right balance, and other complex issues which need to be considered before arriving at an ethical decision.

Research method: A survey was electronically distributed among 229 college students enrolled in the course of Bioethics in 2018. They were asked to examine an actual case and answer three essay questions that followed the description of the case study. The survey was designed to require responders to reflect on the case and use arguments in order to support their answer, rather than immediately choosing from among 4 or 5 possible choices. The essay format was an attempt to receive well thought responses rather than reflex answers. The description of the case was as follows:

"Assume you are a university professor. A female student from a different school has contacted you to report that your colleague, a married man with a child, has deceived her into an affair and then left her with nothing after getting her pregnant. She is now a single mother with little income to support her child and, at the same time, to keep studying at the university until graduation while she cannot ask her family to support her because in her culture (as a Kazakh) it is shameful to have a child without a father. She is heart-broken and resource-less."

Question 1: With enough proof that she is 
telling the truth, is the right of the teacher to privacy and confidentiality more important, or the right of the school to know? Explain your choice. With a little investigation, you realize the same story happened to a Japanese lecturer by the same man. She is also a single mother now working in another school in Tokyo but is upset that she was deceived into an affair with a married man teaching at your university. Both women have chosen not to reveal the identity of the father to their child because they don't want their children to have any relation with an evil man, as they say, in the future.

Question 2: Do you think the children have a right to know who their father is, or the mothers have the right to keep this matter as a private issue and keep it confidential? Explain your choice.

Question 3: With this case as an example among tens of other examples, how would you discuss the right to know versus the right to privacy and confidentiality? Which one is more important and why?

The use of an actual case study helped motivate the students to discuss it seriously and work on arguments that would support their view on the matter. By providing two different perspectives, the privacy right of the teacher (toward the school) and the privacy right of the mothers (toward their children) against the right of the school and the children to know, respectively, the survey enabled the students to consider the conflict from many angles. Finally, they would suggest which right seemed more fundamental to them in general.

Findings and Discussion: Out of 229 students, 222 (\%97) responded to the survey questions. The results of the survey have been summarized in Table 1. As seen in Table 1, the majority of students believed that the school's right to know dominated the right of the teacher to his privacy; 148 students (\%66) considered the right of the school to know more important. Their arguments included the potential of harm to other students including a similar risk to female students, the responsibility of the school to provide a safe environment and to protect students from possible abuse, the social responsibility of teachers to demonstrate higher standards of moral behavior considering the special merits of a professor's position in a university, and the use of deceptive behavior that could have legal ramifications. However, 64 students $(29 \%)$ considered the right of the teacher to his privacy more important. Their arguments included the fact that the student was an adult and thus responsible for her own actions, the matter had not happened on the campus and was thus a personal matter, and that law had not envisioned similar cases of deception as illegal, even though they may not be ethical behavior. There were $10(\% 4)$ students who wanted both the school to know and the privacy of the female student to be protected. Five students $(\% 2)$ believed that the right to privacy and the right to know as in case of the first question were equally important, and thus suggested using a third approach where mediation could be used to reach a satisfactory compromise solution for both the teacher and the single mother, including teacher's financial support for the 
child. The responses of 5 students were not clear and were thus disregarded.

As for the second question regarding the right of the mothers to keep the identity of the father hidden versus the right of the children to know the identity of the father, 144 students $(\% 65)$ in total believed that children had the right to know their father. Their arguments included the inalienable right of every individual to know both their parents, the emotional strain on a fatherless child, and the potential of keeping good relations between a father and his children in the future. Among this group of students, 28 (\%13) students believed that children should know their father but only later when they reached a level of maturity that enables them to understand the complicated situation. However, 59 students (\%26) believed the mothers' right to privacy dominated the children's right to know their biological father. Their arguments included protecting the mother from more emotional burden and stress, the futility of a father who would not financially support his biological children, and possible further risks to both the mothers and children. Sixteen (\%7) students considered both rights to be equally important and thus recommended the use of counselling for the mothers (and also children) to help them make a decision. Three students did not provide a clear response to this question.

As for the third question over the choice of the right to privacy and confidentiality versus the right to know, in general, an overwhelming number of students (125 students, \%56) responded that both rights were important and the decision in each case needs to be reached after careful consideration of circumstances especially the possible consequences, the parties involved, and the nature of conflict. For example, many students referred to the right of privacy over the use of the Internet by people versus the right of the governments to search for terrorism suspects, and the right of people to know about corrupt officials and businesses free of governmental interference. Having stated their concerns, 34 students (\%15) believed that in general the right of individuals to privacy would be a more important issue, and 50 students (\%22) believed that the right to know would provide more benefits and would thus be more important than the right to privacy. Thirteen students $(\% 6)$ provided no clear response to the third question, which might be related to the difficulty they had in choosing a side; however, their answers were too vague and were thus disregarded.

A question in this research was whether students would be able to discuss and argue over the complexity of balancing the right to privacy against the right to know. I hypothesized that the extremely common use of social media platforms such as Facebook among college students would enable them to be familiar with the privacy versus publicity issues over the Internet. The rich arguments and debates submitted by the wide majority of students confirms this point. In the case of Facebook, as an example, when a user determines the level of privacy of his/her own page, and every time he/she decides to confirm or reject a friend request for access to his/her page, and so on and so forth, there 
is a need to balance privacy against the will to publicize one's personal information, sociopolitical views, interests and friendships. The majority of college students in this

Table 1: Results of a survey on 222 college students over the right to privacy and confidentiality vs. the right to know

\section{Q1: Teacher's right to privacy and confidentiality vs. School's right to know about} teacher's actions

64 (\%29) students support teacher's right to privacy

5 (\%2) students consider both rights equally important and suggest mediation instead

(5 students provide no clear answer)

Q2: Mothers' right to privacy and confidentiality vs. Children's right to know their father $59(\% 26)$ students support mothers' right to $116(\% \mathbf{\% 2})$ students support children's right to privacy know their father

28 (\%13) students recommend waiting for child maturity in total $144(\% 65)$ students want the children to ultimately know their father

16 (\%7) students consider both rights equally important and suggest counseling instead (3 students provide no clear answer)

Q3: Right to privacy and confidentiality in general vs. Right to know in general

$\begin{aligned} & \text { 34 (\%15) students see right to privacy as } \\ & \text { more important }\end{aligned}$
$\begin{aligned} & \mathbf{5 0}(\mathbf{\% 2 2}) \text { students see the right to know as } \\ & \text { more important }\end{aligned}$
(13 students consider both rights equally important and suggest case by case
decisions


know. However, no student referred to another approach for achieving such balance, which is in fact a basic discussion when the general topic of rights versus responsibilities is debated.

Let me elaborate; one may try to balance the right to privacy against the responsibility one has regarding transparency. It is not only the government, which should be transparent about its policies and financial transactions. For example, any individual who engages in starting intimate relations with another individual should be transparent about his/her marital status and step by step over other aspects of his/her life in an intimate relationship. Moreover, one may try to balance the right to know (by publicizing information) against the responsibility to respect other individuals and their autonomy to live as they choose. Following on this approach may help us avoid the conflict between the two rights, while maintaining a healthy balance in the execution of these rights regarding the responsibility that comes with them.

Conclusion: This survey demonstrated the ability of college students to engage in serious discussions over complex and controversial situations where the right to privacy and the right to know are in conflict. The majority of students $(\% 65)$ stated that both the right to privacy and the right to know are important, and a balanced decision would depend on the specific situation in each case and the possible consequences that may be envisioned. Interestingly, the students had come up with various lines of argument including a reference to the existing laws, social norms, and a consideration of possible consequences to any decision. For example, some students referred to the futility of informing the school system as it would probably just try to cover it up to protect its image which turned out to be true. It is possible that college students are well aware of the many instances that the right to privacy is constrained by the right to know, as they are facing such decisions on an everyday basis using social media platforms such as Facebook, Instagram, etc.

It is important to consider that while the majority of students had picked a side answering to the first and second question, they had realized that it was not possible to make a general ruling on the third question without having the specifics of the case and the situation in hand. As the majority of students have stated, both of these rights are important in a democratic society and when conflicts appear, the specific circumstances and particularly the consequence of a decision need to be carefully examined. The responses also show that the law does not provide an answer in many instances and therefore, there is a need for ethical debate and decision-making to resolve conflicts.

\section{References:}

1. Cooper, Kent. The Right to Know: An Exposition of the Evils of News Suppression and Propaganda. New York: Farrar, Strauss and Cudahy. 1956.

2. Emerson, Thomas I. Legal Foundations of the Right to Know, Wash. U. L. Q. 1.1976

3. De Mott, John. The People's Right to Know Versus Right of Privacy. Speech: talk presented to the Fineman Discussion Group. Philadelphia, PA. 1978. 
4-. Baker, M. The teacher's need to know versus the student's right to privacy. Journal of Law Education, 1987; 16(1), 71-92.

5- Viano, E. C. The news media and crime victims: The right to know versus the right to privacy. In E. C. Viano (Ed.), Critical issues in victimology: International perspectives. (pp. 24-34). New York, NY, US: Springer Publishing Company. 1992.

6- Harris, R. E. The need to know versus the right to know: Privacy of patient medical data in an information-based society. Suffolk University Law Review. 1997; 30(4): 1183-1218.

7- Wyld D. C., Cappel S. D., and Hallock D. E. The right to know and the right to privacy: HIV testing and health care management. The Health Care Supervisor. 1992; 10(3):56-66.

8- Pape, J. Physician data banks: The public's right to know versus the physician's right to privacy. Fordham Law Review, 1997; 66(3), 975-1028.

9- Borna, S. and Avila, S. Genetic Information: Consumers' Right to Privacy versus Insurance Companies' Right to Know a Public Opinion Survey. Journal of Business Ethics. 1999; 19(4): 355-362.

10- Gross, E. The struggle of democracy against terrorism protection of human rights: The right to privacy versus the national interest the proper balance. Cornell International Law Journal. 2004; 37(1): 27-94.

11- Deloney, W. Unsealing adoption records: The right to privacy versus the right of adult adoptees to find their birthparents. Whittier Journal of Child and Family Advocacy. 2007; 7(1): 117-144.

12- Banisar, David. The Right to Information and Privacy: Balancing Rights and Managing Conflicts. The World Bank. Governance Working Paper Series. 2011.

13- Symons Xavier. The right to know versus the right to privacy: donor anonymity and the Assisted Reproductive Treatment Amendment Act 2016 (Vic). The Medical Journal of Australia. 2017; 207(9): $377-$ 378.

14-Pandiani, John A, Banks, Steven M. and Schacht, Lucille M. Personal privacy versus public accountability: A technological solution to an ethical dilemma. The Journal of Behavioral Health Services Research. 1998; 25(4): 456-463.

15- Crane, A. E. The right to know versus the right to privacy. Annual Survey of American Law. 1986; 3: 645-666.

16- Hirani, Afshin A. A. and Rafiq, Nasreen. Silence in violence: a curse or a goodwill? Eubios Journal of Asian and International Bioethics. 2019; 29(3): 109112.
Author Contributions: The Author conceived the idea, did the literature review and wrote the manuscript. He also checked the manuscript meticulously.

Conflict of interests: No conflict of interest in this study to declare. 